Acta Cryst. (2002). A58 (Supplement), C47

HIGH PRESSURE - HIGH TEMPERATURE STUDIES ON $\mathrm{CO}_{2}$ AND $\mathrm{N}_{2} \mathrm{O}$ SYSTEMS

M. S. Somayazulu

HPCAT, Carnegie Institution of Washington Geophysical Laboratory 5251, Broad Branch Road, Nw Washington DC 20015 USA

The light elements of the first row of the periodic table form simple molecular compounds $\mathrm{N}_{2}, \mathrm{CO}_{2}, \mathrm{~N}_{2} \mathrm{O}, \mathrm{C}_{2} \mathrm{~N}_{2}$ and $\mathrm{CH}_{4}$ that are characterized by strong covalent bonding between atoms which condense to form high symmetry structures characterized by weak van der Waal's interactions. With increasing pressure and temperature these solids are being observed to transform to framework or polymeric solids $[1,3]$ and decompose at high temperatures [13].This talk will focus on the results in the case of $\mathrm{CO}_{2}$ and $\mathrm{N}_{2} \mathrm{O}$ systems. Although the two systems are isoelectronic and display similar high-pressure phases at room temperature, recent work at high P-T conditions has shown that whereas $\mathrm{CO}_{2}$ tends to form a covalently bonded structures [1,3], $\mathrm{N}_{2} \mathrm{O}$ forms an ionic, aragonite type phase $\mathrm{NONO}_{3}$ [2]. On the other hand, recent theoretical studies on these two systems have predicted similar high P-T behavior [4]. The talk will focus on presenting the experimental results comparing the high P-T phase diagrams of these two systems, their structural details and the compressibility of the stable phases to be able to understand and rationalize the observed differences in the two systems.

Acknowledgements: This work is supported by NASA, NSF-DMR, NSLS, APS and the W. M. Keck foundation.

References:

[1] V. Iota et al, Science, 283, 1510 (1999).

[2] M. S. Somayazulu et al, Phys. Rev. Lett. 87, 135504 (2001).

[3] O. Tschauner et al, Phys. Rev. Lett. 87, 75701 (2001).

[4] J. J. Dong et al, Phys. Rev. B 61, 5967 (2000).

Keywords: HIGH PRESSURES HIGH TEMPERATURES, SIMPLE MOLECULAR SYSTEMS, DENSE FRAMEWORK STRUCTURES

Acta Cryst. (2002). A58 (Supplement), C47

\section{HIGH-ENERGY X-RAY DIFFRACTION STUDIES OF OXIDE} GLASSES AT SPring-8

S. Kohara ${ }^{1}$ A. Kajinami ${ }^{2}$ K. Suzuya ${ }^{3}$

1 Japan Synchrotron Radiation Research Institute Materials Science Division 11-1 Kouto, Mikazuki-Cho, Sayo-Gun HYOGO 679-5198 JAPAN ${ }^{2}$ Kobe University ${ }^{3}$ Japan Atomic Energy Research Institute

With the arrival of the latest generation of synchrotron sources and the introduction of advanced insertion devices (wigglers and undulators), the highenergy ( $\mathrm{E}>30 \mathrm{keV}$ ) X-ray diffraction technique has become feasible, leading to new approaches in the quantitative study of the structure of disordered materials. Recently, the high-energy X-ray diffraction data have been combined with neutron diffraction data from a pulsed source to provide more detailed and reliable structural information than that hitherto available. We have developed a two-axis diffractometer for glass, liquid and amorphous materials [1] at the SPring-8 high-energy X-ray diffraction beamline BL04B2 [2]. Furthermore, we have succeeded to analyze the intermediate-range order of network forming glasses, $\mathrm{SiO}_{2}$ [3], $\mathrm{B}_{2} \mathrm{O}_{3}$ [4], and $\mathrm{GeO}_{2}$ by the reverse Monte Carlo (RMC) modeling technique [5] with special focus on the ring structures using both high-energy X-ray and neutron diffraction data. The SPring-8 bending magnet beamline BL04B2 and two-axis diffractometer for disordered materials, and high-temperature furnace designed for the diffractometer will be described, with recent findings on several oxide glasses from ambient to high temperatures.

References

[1] M. Isshiki, Y. Ohishi, S. Goto, K. Takeshita and T. Ishikawa, Nucl. Instr. Meth. A467-468, 663 (2001).

[2] S. Kohara, K. Suzuya, Y. Kashihara, N. Matsumoto, N. Umesaki and I.

Sakai, Nucl. Instr. and Meth. A467-468, 1030 (2001).

[3] S. Kohara and K. Suzuya, Chem Glasses, in press.

[4] K. Suzuya, Y. Yoneda, S. Kohara and N. Umesaki, Phys. Chem Glasses,

41, 282 (2000).

[5] R. L. McGreevy and L. Pusztai, Mol. Simul. 1, 359 (1988).

Keywords: HIGH-ENERGY X-RAY DIFFRACTION STRUCTURE

GLASS
Acta Cryst. (2002). A58 (Supplement), C47

NEW HIGH PRESSURE NITRIDES

A. Zerr $^{1}$ M. Schwarz ${ }^{1}$ R. Schmechel ${ }^{2}$ R. Kolb ${ }^{2}$ H. von Seggern ${ }^{2}$ R. Riedel ${ }^{1}$

${ }^{1}$ Technische Universitat Darmstadt FB Materialwissenschaft, FG Disperse Feststoffe Petersenstr. 23 DARMSTADT 64287 GERMANY ${ }^{2}$ TU-Darmstadt, FB Materialwissenschaft, FG Elektronische

Discovery of a new family of spinel-nitrides $\left(\gamma-\mathrm{Me}_{3} \mathrm{~N}_{4}, \mathrm{Me}=\mathrm{Si}, \mathrm{Ge}, \mathrm{Sn}\right)$ is probably the most significant breakthrough in the high pressure synthesis of new materials in the last years. The attention to these materials was attracted by predictions that $\gamma-\mathrm{Si}_{3} \mathrm{~N}_{4}$ may have high elastic moduli and hardness. $\gamma-\mathrm{Si}_{3} \mathrm{~N}_{4}$ was also suggested as a candidate material for fabrication of blue light emitting diodes because its band gap was calculated to be $3.45 \mathrm{eV}$. Our recent experiments on the above subjects gave following results: (i) the bulk modulus of $\gamma-\mathrm{Si}_{3} \mathrm{~N}_{4}$, obtained from compression experiments in a DAC to $53 \mathrm{GPa}$, was found to be $290 \mathrm{GPa}$. (ii) Applying nanoindentation technique, we determined the shear modulus of $\gamma-\mathrm{Si}_{3} \mathrm{~N}_{4}$ to be $148 \mathrm{GPa}$ and the hardness between 30 and $43 \mathrm{GPa}$. This hardness value is similar to that of $\mathrm{SiO}_{2}$-stishovite, the third hardest material after diamond and cubic $\mathrm{BN}$. (iii) The band gap of $\gamma-\mathrm{Si}_{3} \mathrm{~N}_{4}$ is about $3.3 \mathrm{eV}$, derived from measurements of its optical transmission spectra and cathodoluminescence. (iv) the advantage of $\gamma-\mathrm{Si}_{3} \mathrm{~N}_{4}$ in comparison to diamond, cubic $\mathrm{BN}$ and $\mathrm{SiO}_{2}$-stishovite is its thermal stability in air and in contact with ferric alloys to at least $1000^{\circ} \mathrm{C}$. In further experiments a novel high pressure $\delta$-phase of $\mathrm{Si}_{3} \mathrm{~N}_{4}$ was observed on compression of $\beta-\mathrm{Si}_{3} \mathrm{~N}_{4}$ above $34 \mathrm{GPa}$. The phase transition was verified by Raman spectroscopy and X-ray powder diffraction. We also succeeded in synthesis of a quaternary oxonitride $\mathrm{Si}_{2} \mathrm{AlON}_{3}$ with spinel-structure, which exhibits a high hardness of about 28 $\mathrm{GPa}$.

Keywords: SPINEL-NITRIDES $\mathrm{Si}_{3} \mathrm{~N}_{4}$ PROPERTIES

\section{Acta Cryst. (2002). A58 (Supplement), C47 \\ WHAT CAN NEUTRON DIFFRACTION AND CHEMICAL CRYSTALLOGRAPHY TELL US ABOUT GLASS STRUCTURE? A.C. Hannon \\ ISIS Facility Rutherford Lab Chilton Didcot Oxon OX11 0QX UK}

Pulsed neutron diffraction is an invaluable tool for investigating the structure of disordered materials, since it yields a high resolution in real-space. Recent data on calcium aluminates and other glasses are used to demonstrate the power of pulsed neutrons to probe glass structure, and it is shown that the methods of chemical crystallography may be applied to a consideration of glass structure. Particular emphasis is given to the structural role of the anions (e.g. oxygen). By considering the environment of oxygen, which is often coordinated by three cations, a complete description can be developed of the network connectivity in oxide glasses.

\section{Keywords: GLASS NEUTRON DIFFRACTION NON-CRYSTALLINE MATERIALS}

